\title{
PELAKSANAAN STANDAR OPERASIONAL PROSEDUR PEMESANAN MAKANAN DI PRIME STEAK HOUSE FINE DINING RESTORAN JW MARRIOTT HOTEL MEDAN
}

\author{
Ivan Benedict Tambunan, \\ E-mail : ivanbenedict303@gmail.com \\ Tourism And Hotel Academy of Darma Agung
}

\begin{abstract}
ABSTRAK
Fine Dining merupakan konsep makan ala restoran yang menawarkan suasana mewah dan pelayanan berkelas.Tahapan penyajian makanan di Restoran Fine Dining di mulai dari Appetizer sampai Dessert.Pengunjung yang datang biasanya menggunakan pakaian yang rapi dan formal.Pria menggunakan pakaian kemeja, jas dan untuk wanita menggunakan gaun dan pakaian yang mewah.Dalam melayani tamu agar tamu puas maka diperlukan pelaksanaan standar operasional prosedur oleh pramusaji. Pramusaji sebaiknya melaksanakan tahapantahapan dalam melayani tamu yang memesan makanan di Prime Steak House Fine Dining Restaurant JW Marriott Hotel Medan'

Untuk mendapatkan data yang lebih akurat penulis melakukan peninjauan secara langsung ke objek yang akan diteliti dengan menggunakan jenis penilitian deskriptif dengan melakukan observasi dan wawancara kepada tamu sebanyak 15 orang. Penelitian ini dilaksanakan selama 6 (enam) bulan, terhitung mulai bulan Agustus 2019 sampai Februari 2020 .

Dari hasil analisa penulis ditemukan bahwa pramusaji masih kurang melaksanakan standar operasional prosedur pemesanan makanan di Prime Steak Fine Dining Restaurant yang mengakibatkan tamu kurang puas selama berada di restaurant. Pelaksanaan prosedur pemesanan makanan sudah ditetapkan di Prime Steak House Fine Dining Restoran namun masih ada pramusaji yang tidak melakukan tugasnya dengan baik dan maksimal misalnya kesalahan dalam mencatat pesanan makanan atau taking order, tidak menawarkan dessert, dan tidak menginformasikan kepada tamu waktu yang dibutuhkan untuk makanan diterima tamu.
\end{abstract}

\section{Keywords: Standar Operasioal Prosedur, Fine Dining Restaurant, Pramusaji.}

\section{PENDAHULUAN}

\section{A.Latar Belakang Masalah}

Industri pariwisata memegang peranan yang cukup penting dalam pembangunan ekonomi, misalnya membuka lapangan pekerjaan dan meningkatkan devisa negara serta industri pariwisata juga dianggap sebagai salah satu cara untuk mempromosikan suatu negara kepada negara lainnya. Salah satu komponen yang besar di Indonesia adalah usaha perhotelan.
Hotel adalah sebuah bangunan yang menyediakan pelayanan jasa penginapan, makanan dan minuman serta jasa-jasa lainnya yang dikelola secara komersial.Hotel memiliki beberapa departemen salah satunya adalah Food and Beverage Service Department.Restoran adalah suatu usaha yang bergerak dalam bidang pelayanan jasa makanan dan minuman.Food and Beverage Service Department memegang peranan penting dalam operasional hotel, dalam arti departemen ini merupakan suatu 
departemen yang banyak mendatangkan keuntungan bagi hotel, karena tamu yang menginap di hotel tidak hanya memerlukan jasa penginapan tetapi juga memerlukan makanan dan minuman.

Fine Dining merupakan konsep makan ala restoran yang menawarkan suasana mewah dan pelayanan berkelas. Tahapan penyajian makanan di Restoran Fine dining dimulai dari Appetizer sampai Dessert. Fine Dining menyajikan makanan Western yang harganya relatif mahal, biasanya terdiri dari makanan steak, pasta, salad, soup, dessert dan lain - lain. Menyajikan minuman alkohol seperti bir, liquor, mocktail, cocktail, dan berbagai macam wine (anggur).Pengunjung yang datang biasanya menggunakan pakaian yang rapi dan formal.Pria menggunakan pakaian kemeja, jas dan untuk wanita menggunakan gaun dan pakaian yang mewah.Setiap restoran memiliki Standar Operasional Prosedur Pemesanan Makanan yaitu langkah-langkah dalam memberikan pelayanan terhadap tamu mulai dari mengantarkan tamu ke meja sampai memberikan bon pembayaran kepada tamu.Salah satu tujuan dari Standar Operasional Prosedur Pemesanan Makanan adalah untuk memberikan keseragaman dalam melayani para tamu di restoran. Jika Standar Operasional Prosedur ini dilaksanakan dengan baik maka operasional restoran akan berjalan dengan lancar.

Dalam melaksanakan pelayanan kepada tamu di Restoran Fine Dining menuntut setiap pramusaji harus dapat mengikuti prosedur dengan baik agar pelayanan kepada tamu dapat terlaksana dan tamu merasa puas dengan pelayanan yang diberikan.Pramusaji dituntut memiliki skill (keahlian) dalam melayani tamu. Standar Operasional Prosedur Pemesanan Makanan di Prime Steak House Fine Dining
Restoran adalah langkah - langkah tahapan atau pedoman dalam melayani tamu yang harus dilaksanakan pramusaji.Pramusaji diharapkan senantiasa melaksanakan Standar Operasional Prosedur Pemesanan Makanan yang telah ditetapkan.Menjalankan Prosedur di Restoran dengan baik menuntut pengawasan yang baik dari Supervisor ditemukan banyak kesalahan yang dilakukan oleh Pramusaji dalam elayani tamu di restoran. Pramusaji kurang sadar dalam melaksanakan Standar Operasional Prosedur Pemesanan Makanan di Fine Dining Restoran seperti hal kesalahan dalam mencatat pesanan makanan atau taking order, tidak menawarkan dessert, dan tidak menginformasikan kepada tamu waktu yang dibutuhkan untuk makanan diterima tamu sehingga menyebabkan tamu kurang puas terhadap pelayanan yang diberikan.

Agar Pelaksanaan Standar Operasional Prosedur Pemesanan Makanan dapat dijalankan oleh pramusaji maka dibutuhkan juga pengawasan yang baik dari supervisor terhadap pramusaji.Pramusaji yang tidak melaksanakan Standar Operasional Prosedur Pemesanan Makanan dengan baik dapat mengakibatkan kecewa (complain) dari tamu.Oleh karena itu, betapa pentingnya melaksanakan prosedurprosedur pelayanan yang sesuai dengan Standar Operasional Prosedur (SOP) Prime Steak House Fine Dining Restoran JW Marriott Hotel Medan untuk kepuasan tamu.

\section{B. Identifikasi Masalah}

Dari uraian latar belakang permasalahan yang telah disampaikan, penulis mengidentifikasikan bahwa terdapat permasalahan mengenai pelaksanaan standar operasional prosedur dalam 
pemesanan makanan kepada tamu.Adapun identifikasi masalah yang menjadi kajian penulis dalam penelitian ini adalah :

1. Standar Operasional Prosedur Pemesanan Makanan di Prime Steak HouseFine Dining Restoran yang masih belum dijalankan dengan baik oleh pramusaji.

2. Pelaksanaan Prosedur Pemesanan Makanan di Prime Steak House Fine Dining Restoran yang masih belum dilaksanakan sepenuhnya.

3. Pengawasan Supervisor terhadap Pelaksanaan Prosedur Pemesanan Makanan di Prime Steak House Fine Dining Restoran yang masih perlu untuk ditingkatkan agar operasional dapat berjalan dengan maksimal.

\section{Rumusan Masalah}

Dari paparan diatas adapun yang menjadi rumusan masalah yaitu:

1.Bagaimana Standar Operasional Prosedur Pemesanan Makanan di Prime Steak House Fine Dining Restoran JW Marriott Hotel Medan?

2.Bagaimana Pelaksanaan Prosedur Pemesanan Makanan di Prime Steak House Fine Dining Restoran JW Marriott Hotel Medan?

3.Bagaimana Pengawasan Supervisor terhadap Pelaksanaan Prosedur Pemesanan Makanan di Prime Steak House Fine Dining Restoran?

\section{Tujuan Penelitian}

Didalam penyusunan karya tulis ini penulis memiliki beberapa tujuan diantaranya adalah sebagai berikut :
1.Untuk
mengetahui
Standar

Operasional Prosedur Pemesanan Makanan di Prime Steak House Fine Dining JW Marriott Hotel Medan

2.Untuk mengetahui Pelaksanaan Prosedur Pemesanan Makanan di Prime
Steak House Fine Dining Restoran JW Marriott Hotel Medan

3.Untuk mengetahui Pengawasan Supervisor terhadap Pelaksanaan Prosedur Pemesanan Makanan di Prime Steak House Fine Dining Restoran.

\section{E. Manfaat Penelitian}

1. Dapat memberikan manfaat sebagai bahan referensi bagi pengembangan ilmu perhotelan, khususnya bidang pelayanan restoran.

2.Diharapkan menambah wawasan khususnya bagi para karyawan perhotelan dalam menerapkan standar operasional prosedur di Fine Dining Restaurant.

3.Diharapkan bermanfaat bagi karyawan perhotelan dan restoran dalam melaksanakan prosedur pelayanan supaya dapat menciptakan kepuasaan tamu.

\section{LANDASAN TEORI}

\section{A. TINJAUAN PUSTAKA}

1.Pengertian Standar Operasional Prosedur Standar Operasional Prosedur merupakan dokumen yang berkaitan dengan Prosedur yang dilakukan secara kronologi untuk menyelesaikan pekerjaan yang bertujuan untuk memperoleh hasil kerja yang paling efektif dari para pekerja dengan biaya yang serendah-rendahnya.

\section{Pengertian Standar}

Pengertian Standar menurut Kamus Besar Bahasa Indonesia (2008: 1375) kata Standar diberi beberapa arti antara lain (1) ukuran tertentu yang dipakai sebagai patkan, (2) ukuran atau tingkat biaya hidup, (3) sesuatu yang dianggap tetap nilainya sehingga dapat dipakai sebagai ukuran nilai (harga), (4) menjadikan 
standar, pembekuan atau pedoman yang telah ditetapkan.

\section{Pengertian Operasional}

Menurut Kamus Besar Bahasa Indonesia (2008: 1020) “Operasional adalah operasi yang didasarkan pada aturan; Operasi yang sesuai dan tidak menyimpang dari suatu norma atau kaidah."

\section{Pengertian Prosedur}

Pengertian Prosedur menurut Mulyadi (2013: 1050) "Prosedur adalah Suatu urutan kegiatan krelikal, biasanya melibatkan beberapa orang dalam satu departemen atau lebih, yang dibuat untuk menjamin penanganan secara seragam transaksi perusahaan yang terjadi berulangulang."

Dari ketiga pengertian tersebut diatas bahwa Standar Operasional Prosedur (SOP) menurut Tjipto Atmoko (2011: 2) merupakan suatu pedoman atau acuan untuk melaksanakan tugas pekerjaan sesuai dengan fungsi dan alat penilaian kinerja instansi pemerintah berdasarkan indikatorindikator teknis, administratif dan prosedural sesuai tata kerja, prosedur kerja dan sistem kerja pada unit kerja yang bersangkutan. Sedangkan Standar Operasional Prosedur Pemesanan makanan secara umum adalah sebagai berikut:

1. Mengantarkan tamu ke meja yang sudah siap digunakan, pilihkan tempat duduk sesuai jumlah pelanggan. Tarikan kursi dan persilahkan tamu duduk, utamakan wanita, anak-anak, dan orangtua.

2.Berdiri sempurna minimal 1 langkah dari meja tamu. Jangan menekuk atau melipat kaki. Sikap disiplin akan memberi kesan yang baik kapada tamu.

3.Memberikan Menu, Memberikan menu makanan dan minuman dari sebelah kiri tamu agar tamu mudah menerimanya dengan tangan kanan.

4.Mendengarkan dengan baik dan tulis pesanannya pada buku pesanan

5.Pisahkan antara pesanan makanan dan minuman

6.Konfirmasikan pesanan tamu

Setelah tamu selesai pesan, maka baca kembali apa yang sudah dicatat untuk konfirmasi apabila terjadi kesalahan atau kekeliruan pencatatan pesanan.

\section{PengertianFine Dining}

Fine Dining merupakan sebuah restoran yang sangat mengutamakan pelayanan terhadap tamunya. Tahapan penyajian makanan di Restoran Fine dining dimulai dari Appetizer sampai Dessert. Pengunjung yang datang biasanya menggunakan pakaian yang rapi dan formal.Pria menggunakan pakaian kemeja, jas dan untuk wanita menggunakan gaun dan pakaian yang mewah.

6.Pengertian Restoran

Menurut Masrum W.A dalam Ivan Benedict (2020: 10) "Pengertian Restoran adalah suatu tempat atau bangunan yang diorganisasikan secara komersial, yang menyelenggarakan pelayanan dengan baik kepada semua tamunya baik berupa makan maupun minum."

\section{Pengertian Pemesanan Makanan}

Pemesanan atau Taking Order adalah kegiatan menerima dan mencatat pesanan tamu. Dalam hal ini makanan dan minuman, yang selanjutnya akanditeruskan ke bagian yang terkait antara lain dapur, bar, dan kasir.

\section{METODE PENELITIAN Jenis Penelitian}


Bentuk penelitian ini adalah deskriptif, yaitu datang langsung ke lokasi untuk mengambil dan mencari data yang kemudian data tersebut digabung dengan data yang telah diperoleh sebelumnya.Metode deskriptif adalah suatu metode penilitian yang bersifat menggambarkan kenyataan atau fakta sesuai data yang diperoleh.

\section{Waktu dan Lokasi Penelitian}

Dalam melakukan penelitian penulis memaksimalkan waktu selama 6 (enam) bulan mulai 01 Agustus 2019 sampai dengan 01 Februari 2020 di Food and Beverage Service Department bagian Prime Steak House Restoranpada Hotel JW Marriott Hotel Medan berlokasi di Jln. Putri Hijau No.10, Kesawan, Kec. Medan Baru, Kota Medan, Sumatera Utara 20111.

\section{Populasi dan Sampel}

\section{Populasi}

Dalam Kamus Besar Bahasa Indonesia (2008: 1094) Populasi adalah sekelompok orang, benda, atau hal yang menjadi sumber pengambilan sampel, kumpulan yang memenuhi syarat tertentu terkait dengan masalah yang diteliti. Total populasi yang diteliti adalah tamu sebanyak 15 orang.

\section{Sampel}

Menurut Dr.Sugiyono dalam Ivan Benedict (2020: 12) "Sampel adalah bagian darijumlah atau karakteristik yang dimiliki sehari-hari oleh populasi tersebut.Adapun Sampel dari penelitian yang dilakukan adalah tamu sebanyak 15 orang."

\section{Teknik Pengumpulan Data}

Untuk memperoleh data yang lengkap dan akurat dalam penyusunan karya tulis, penulis menggunakan 2 (dua) macam metode penelitian yaitu:
Penelitian Kepustakaan (Library research) Yaitu penelitian yang dilakukan dengan mengumpulkan data-data dari buku-buku yang berhubungan dengan masalah tentang kelayakan suatu restoran.

Penelitian lapangan (Field research)

Yaitu penelitian yang dilakukan secara langsung pada objek yang akan diteliti, mengadakan observasi langsung, wawancara kepada pramusaji dan penyebaran angket kepada tamu.

\section{ANALISIS MASALAH}

\section{Standar Operasional Prosedur} Pemesanan Makanan di Prime Steak House Fine Dining Restoran JW
Marriott Hotel Medan

Prime Steak House Fine Dining Restoran adalah salah satu outlet foodandbeverage service di JW Marriott Hotel Medan. Prime Steak House mempunyai kapasitas 84 pax, Penawaran makanan disajikan dalam bentuk hidangan pilihan (A la Carte Menu) dan Set Menu.

Dalam melaksanakan Pelayanan terhadap tamu di Prime Steak House Fine Dining Restoran pramusaji harus senantiasa mengikuti Standar Operasional Prosedur agar dapat bekerja dengan maksimal mengikuti ketentuan yang telah ditetapkan oleh pihak Manajemen. Dalam memesan makanan untuk tamu terdapat Standar Operasional Prosedur yang dimulai dari Mempersiapkan pulpen yang berlogo JW Marriott, mengucapkan greeting (mengucapkan salam) memperkenalkan diri kepada tamu, memberi informasi kepada tamu tentang menu special di restoran, menawarkan wine, menawarkan dessert, dan melakukan repeat order serta tersenyum pada saat melayani tamu.

Persiapan Peralatan di Prime Steak House Fine Dining 
Sebelum kegiatan pelayanan dilakukan di Prime Steak House Fine Dining adalah dengan mempersiapkan dan melengkapi segala jenis perlengkapan yang dibutuhkan pada waktu operasional seperti Bread and butter Plate, Bread and Butter Knife, Dessert Fork, Dinner fork, Show plate, Napkin, Dessert Knife, Dinner Knife, Soup spoon, Steak Knife, Water Goblet, Red Wine, dan White Wine Goblet sudah dalam keadaan bersih dan siap untuk digunakan. Sedangkan Red Wine dan Lampu berbentuk telur diletakkan diatas meja setelah selesai Pramusaji break. Restoran buka mulai Weekday jam 18.30 - 22.30 dan Weekendjam 18.30 - 23.00 Persiapan peralatan dilakukan mulai dari jam 12.00 16.00 dengan berbagai kegiatan yang meliputi pembersihan area, pengaturan meja, kursi, persiapan peralatan alat-alat makanan, minuman dan penataan meja makan.

\section{Makanan yang tersedia di Prime Steak House Fine Dining}

Makanan yang ada di restoran dibuat dalam satu daftar buku menu, dimana menu tersebut terdapat menu-menu makanan dimulai dari appartizer sampai dessert.

Menu Makanan yang tersedia di Prime Steak House JW Marriott Hotel Medan

\section{Pelaksanaan Prosedur Pemesanan} Makanan di Prime Steak House Fine Dining Restoran JW Marriott Hotel Medan

Berikut Teknik pelaksanaan Prosedur Pemesanan Makanan di Prime Steak House Fine Dining JW Marriott Hotel Medan, Terdapat 7 langkah penting yang harus diingat dan dilaksanakan oleh Pramusaji:

1. Setelah tamu duduk, waiters menghampiri tamu dan memberikan daftar menu A la carte. Utamakan wanita terlebih dahulu atau orang yang paling tua. ("Selamat Malam ibu bapak, saya sebagai pramusajihari ini, kami mempunyai menu spesial Unlimited Fries and Salad, Jika ibu dan bapak memilih segala steak yang terdapat di menu, mendapatkan kentang goreng dan salad sepuasnya setiap hari kamis dan jumat")

Jika tamu tidak tertarik dengan menu spesial, tawarkan daftar menu.

1.MenawarkanWine Menu dan Menu minuman

Di Prime Steak House Fine Dining Restoran setelah meletakkan Wine Menu, dan Menu minuman diatas meja.Waiters harus memberikan saran yang terbaik sesuai selera tamu. Sebelum melakukan pemesanan makanan waiters harus mempersiapkan Pulpen berlogo JW Marriott dan Captain Order JW Marriott

\section{Writting The Captain Order}

Waktu mengambil pesanan tamu, waiters harus mendengarkan baik-baik pesanan tamu agar tidak terjadi kesalahan dalam mencatat pesanan makanan. Dalam penulisan pesanan tamu di Captain Order menggunakan istilah atau singkatan kata secara jelas dan sistematis untuk mempermudah pihak kitchen dan bar dalam menyediakan pesanan sesuai yang tertulis di captain order. Contoh jika tamu memesan menu steak seorang waiters harus menulis singkatan untuk kematangan daging steak tersebut misalnya $\mathrm{R}$ (rare). Tujuan dari menuliskan singkatan menu di captain order untuk mempermudah dan mempersingkat waiters dalam taking order kepada tamu. Setelah semua pesanan tamu dicatat dengan jelas di Captain Order lalu waiters harus menginformasikan waktu yang dibutuhkan tamu, mengulangi atau 
membacakan kembali pesanan tersebut untuk menyakini kebenaran pesanan tamu sebelum diproses lanjut dan menghindari kesalahan dalam taking order sehingga tidak terjadi adanya complaint tamu.

\section{Menawarkan Dessert kepada tamu}

Waiters diwajibkan menawarkan Dessert kepada tamu setelah maincourse.

\section{Presenting Bill}

Ketika tamu sudah selesai makan dan minum, Waiters harus memberikan bon pembayaran jika tamu sudah memintanya.Sediakan pulpen JW Marriott dan bon pembayaran. Untuk prosedur pembayaran kartu kredit tamu menandatangani slip kartu kredit dan bon pembayaran dan memberikan salah satu bon kepada tamu. Untuk Pembayaran tunai, Waiters datang ke meja tamu dan menghitung jumlah uang.Pastikan kepada tamu agar tidak terjadi kesalahan dan mengucapkan terimakasih.

\section{KESIMPULAN DAN SARAN Kesimpulan}

JW Marriott Hotel Medan merupakan salah satu hotel bintang lima yang berskala internasional di kota Medan. Hotel ini memliki standar fasilitas dan pelayanan bintang lima khususnya, di Prime Steak House Fine Dining Restoran JW Marriott Medan. Prime Steak House Fine Dining restoran memiliki peranan penting dalam pelayanan Food and Beverage Service di JW Marriott Medan. Berdasarkan uraian pada bab sebelumnya, setelah menganalisis keseluruhan data yang diperoleh. Maka penulis dapat menarik kesimpulan yaitu:

Prosedur pemesanan makanan sangat berpengaruh terhadap kepuasan tamu dan kelancaran operasional restoran.Prosedur dimulai dari menghampiri tamu dan memberikan daftar menu A la carte sampai Presenting Bill.Sebelum kegiatan pelayanan dilakukan di Prime Steak House Fine Dining adalah dengan mempersiapkan dan melengkapi segala jenis perlengkapan yang dibutuhkan pada waktu operasional.

Pelaksanaan prosedur pemesanan makanan sudah ditetapkan di Prime Steak House Fine Dining Restoran namun masih ada pramusaji yang tidak melakukan secara keseluruhan misalnya kesalahan dalam mencatat pesanan makanan atau taking order, tidak menawarkan dessert, dan tidak menginformasikan kepada tamu waktu yang dibutuhkan untuk makanan diterima tamu.

Pengawasan Supervisor sangat perlu dilakukan untuk mengetahui proses pekerjaan yang dilakukan di Prime Steak House Fine Dining Restoran yang melaksanakan pengawasan terhadap pramusaji oleh supervisor. Pelaksanaan pengawasan yang dilakukan supervisor Prime Steak House adalah melakukan pendekatan kepada pramusaji, mengikuti operasional, dan mengadakan observasi.

\section{Saran}

Dalam penulisan karya tulis ini, penulis menuliskan beberapa saran yang dapat digunakan sebagai masukan yang bersifat positif dan membangun bagi Hotel JW Marriott Medan khususnya pada Prime Steak House Fine Dining Restoran yaitu:

Lebih dipererat kerja sama antara karyawan (teamwork) dalam memberikan pelayanan kepada tamu, sehingga benarbenar melaksanakan tugas agar sesuai dengan standar prosedur di Prime Steak House Fine Dining Restoran.

Sebaiknya pramusaji tetap mengikuti standar operasional prosedur bahkan lebih 
meningkatkan kualitas pelayanan yang diberikan kepada tamu karena berpengaruh terhadap citra dan nama baik hotel. Diharapkan Supervisor agar tetap meningkatkan pengawasan terhadap pramusaji agar tidak terjadi kesalahan dalam menangani pesanan tamu.

\section{DAFTAR PUSTAKA}

Atmoko, Tjipto, 2011, Standar Operasional Prosedur (SOP) dan Akuntabilitas Kinerja Instansi Pemerintah, Unpad, Bandung.

Bagyono, 2003, Kantor Depan Hotel (Hotel Front Office), Bandung, Alphabeta

Djoko, Sibroto F.Y, 2003, Food \& Beverage and Table Setting, Jakarta, PT Grasindo.

Ivan Benedict 2020, Jurnal Akomodasi Agung Volume VII No.1/APRIL/

Komar, Richard, 2005, Hotel management (Manajemen Perhotelan), Jakarta, PT Grasindo. 